\title{
Deteksi Kadar Alkohol Menggunakan Sensor MQ3 Berbasis Website
}

\author{
Munaf Ismail $^{{ }^{*} \text {, Arief Marwanto }}{ }^{1}$, Muhamad Haddin ${ }^{3}$ \\ 1,2,3Program Studi Teknik Elektro, Universitas Islam Sultan Agung Semarang \\ 1,2, 3Jln. Raya kaligawe Km 4, Semarang 50112, Indonesia \\ E-mail: munaf@unissula.ac.id ${ }^{1}$, arief@unissula.ac.id ${ }^{2}$, haddin@ unissula.ac.id ${ }^{3}$
}

\begin{tabular}{ll}
\hline \hline & Abstrak \\
\hline Info Naskah: & Menurut Kepala Kepolisian Negara Republik Indonesia (Kapolri) Jendral Polisi \\
Naskah masuk: 30 November 2020 & Idham Azis jumlah kematian dari kecelakaan yang terjadi tahun 2019 mencapai \\
Direvisi: 19 Maret 2021 & 23.530 korban meninggal. Total 40\% dari angka kematian akibat kecelakaan lalu \\
Diterima: 12 April 2021 & lintas disebabkan oleh kesalahan manusia dan pengaruh alkohol. Tingginya angka \\
& kematian dari kecelakaan lalu lintas akibat pengaruh alkohol menjadi keprihatinan \\
& kita semua. Konsumsi alkohol berlebihan berbahaya saat berkendara karena \\
& mengkonsumsi alkohol akan mempengaruhi perangai seseorang dan memperburuk \\
& perilaku berkendara karena menurunkan kesadaran sehingga terjadi kecelakaan. \\
& Diperlukan sistem yang mampu mendeteksi kadar alkohol dari pengendara \\
& kendaraan yang dapat di monitor dimana saja, sebagai informasi untuk memberi \\
& peringatan pengendara kendaraan dalam pengaruh alkohol guna mencegah \\
& kecelakaan lalu lintas secara daring berbasis web. Menggunakan sensor MQ-3 \\
& sebagai deteksi kadar alkohol dan prosesor ESP8266 dalam WeMos WiFi. Rata-rata \\
& persentase error pengukuran dari sample yang diukur didapati nilai errornya sebesar: \\
& $3,6 \%$. Penelitian juga berhasil membaca kadar alkohol melalui website.
\end{tabular}

\begin{tabular}{ll}
\hline Keywords: & Abstract \\
alkohol; & According to the Head of the Indonesian National Police (Kapolri) General Idham \\
Azis, the number of deaths from accidents that occurred in 2019 reached 23,530. A \\
total of $40 \%$ of the deaths from traffic accidents are caused by human error and the \\
influence of alcohol. The high number of deaths from traffic accidents due to the \\
influence of alcohol is a concern for all of us. Excessive alcohol consumption is \\
dangerous when driving because consuming alcohol will affect a person's \\
temperament and worsen driving behavior by reducing awareness, leading to \\
accidents. A system that is able to detect the alcohol level of a vehicle driver that can \\
be monitored anywhere is needed, as information to alert motorists to the influence \\
of alcohol in order to prevent traffic accidents online and on a web-based basis. \\
Using the MQ-3 sensor for alcohol detection and the ESP8266 processor in WeMos \\
WiFi. The average percentage error in the measurement of the measured sample was \\
found to have an error value of: $3.6 \%$. Research has also succeeded in reading \\
alcohol levels through websites.
\end{tabular}

\footnotetext{
*Penulis korespondensi:

Munaf Ismail
}

E-mail: munaf@unissula.ac.id 


\section{Pendahuluan}

Minuman alkohol dapat menurunkan kesadaran seseorang. Ketika seseorang mengemudikan kendaraan akan sangat berbahaya apabila dalam pengaruhi minuman alkohol, hal ini dapat menyebabkan kecelakaan lalu lintas. Menurut Kepala Kepolisian Negara Republik Indonesia (Kapolri) Jendral Polisi Idham Azis jumlah kecelakaan lalu lintas sepanjang tahun 2019 mencapai 107.500 kejadian. Sedangkan jumlah kematian dari kecelakaan yang terjadi tahun 2019 mencapai 23.530. korban meninggal [1]. Total $40 \%$ dari angka kematian akibat kecelakaan lalu lintas disebabkan oleh kesalahan manusia dan pengaruh alkohol 1. Tingginya angka kematian dari kecelakaan lalu lintas akibat pengaruh alkohol menjadi keprihatinan kita semua. Konsumsi alkohol berlebihan menjadi berbahaya saat berkendara karena mengkonsumsi alkohol akan mempengaruhi perangai seseorang yang akan memperburuk perilaku berkendara karena tidak sadar yang mengakibatkan terjadinya kecelakaan. Bahkan alkohol atau etanol apabila dikonsumsi secara terus menerus dengan jumlah yang berlebihan akan menyebabkan kegagalan sistem pernafasan dan kematian.

Penelitian terdahulu sudah meneliti alat pengukur kadar alkohol pada manusia dengan beberapa metode, pertama menggunakan sensor MQ-3 dengan tampilan di LCD untuk mengukur kadar alkohol pada nafas manusia [2]. Sensor MQ-3 pada penelitian terdahulu sering digunakan sebagai sensor deteksi alkohol karena sensor MQ-3 akurat sebagai pendeteksi alcohol [3]. Informasi kadar alkohol langsung ditampilkan dalam layar LCD. Hasil penelian tersebut adalah sebuah alat deteksi kadar alkohol yang berdiri sendiri belum tersambung dengan jaringan seluler atau jaringan internet.

Penelitian lainya adalah adalah pendeteksi kadar alkohol pengemudi menggunakan arduino dan pemrogaman dan pengolahaya hasilnya menggunakan LabVIEW [4]. Penelitian tersebut peralatan arduino dan sensor sebagai perangkat keras system sudah tersambung dengan computer untuk membaca dan mengolah pembacaan kadar alkohol melalui software Lab ViEW. Data yang dikirim arduino didapat dari pembacaan langsung pengemudi kendaraan untuk dianalisa tinggi rendahnya kadar alkohol dengan software LabVIEW dalam aplikasi software Arduino Compatible Compiler for LabVIEW (ACCL). Monitoring kadar alkohol dilakukan di komputer yang sudah terinstal alplikasi LabVIEW. Penelitian ini juga belum tersambung dengan jaringan seluler atau jaringan internet.

Penelitian serupa lainya adalah pemanfaatan jaringan internet berbasis aplikasi android untuk memonitor pengemudi kendaraan secara daring bisa dimonitor dimana saja dan kapan saja. Prinsip kerjanya seperti GPS traker dengan monitoring di aplikasi android. Penelitian ini sudah tersambung dengan jaringan internet tetapi hanya monitoring menggunakan smartphone android, tidak dapat dimonitor menggunakan komputer atau smartphone berbasis selain android [5].

Penelitian serupa lainya adalah monitoring gas pada ruang laboratorium secara real time [6]. Untuk mencegah gas-gas yang berbahaya dalam ruangan laboratorium yang sensitif terhadap gas-gas tertentu. Kelebihan penelitian ini adalah pengukuran kadar gas-gas berbahaya dilakukan secara real time hasilnya secara cepat akan ditampilkan dan diolah untuk langkah selanjutnya.

Kebutuhan saat ini adalah sistem monitoring atau alat ukur yang dapat melihat langsung kadar alkohol melalui layar display LCD dan dapat dimoitoring secara nirkabel melalui jaringan internet. Sehingga dapat dimonitor melalui smartphone atau perangkat lainya. Aplikasi Web dapat melakukan monitoring atau pengukuran kadar alkohol dimana saja dan kapan saja dengan berbagai macam peralatan gadget yang hasil pengukuranya dapat diketahui secara cepat. Kebutuhan diatas dapat dijawab dengan embedded system berupa kombinasi software aplikasi web sebagai interface aplikasi daring dan hardware untuk pengukuran kadar alkohol.

Berdasarkan latar belakang yang diuraikan bahwa kebutuhan monitoring kadar alkohol perlu di kembangkan dengan disesuaikan perkembangan teknologi saat ini. Dari rumusan masalah dapat diketahui kebutuhan monitoring kadar alkohol yang menggunakan perangkat keras sensor elektronika, kemudian dapat dimonitor dari jarak jauh dan dimana saja dan dapat diakses cepat yaitu menggunakan aplikasi software yang terkoneksi secara online. Sehingga penelitian ini fokus pada prototype pengukur kadar alkohol. Penelitian ini juga mempunyai batasan batasan dalam pembahasannya. Batasan tersebut adalah mengunakan sensor elektronika MQ-3 dan koneksi perangkat sensor kadar alkohol untuk ditampilkan di Web menggunakan jaringan internet.

\section{Metode}

\subsection{Tahapan Penelitian}

Rancangan sistem deteksi alkohol berbasis web ini terdiri dari rangkaian hardware dan aplikasi software. Blok diagram sistem deteksi alkohol menggunakan sensor MQ-3 berbasis web terdiri dari beberapa bagian seperti terlihat pada gambar 1 .

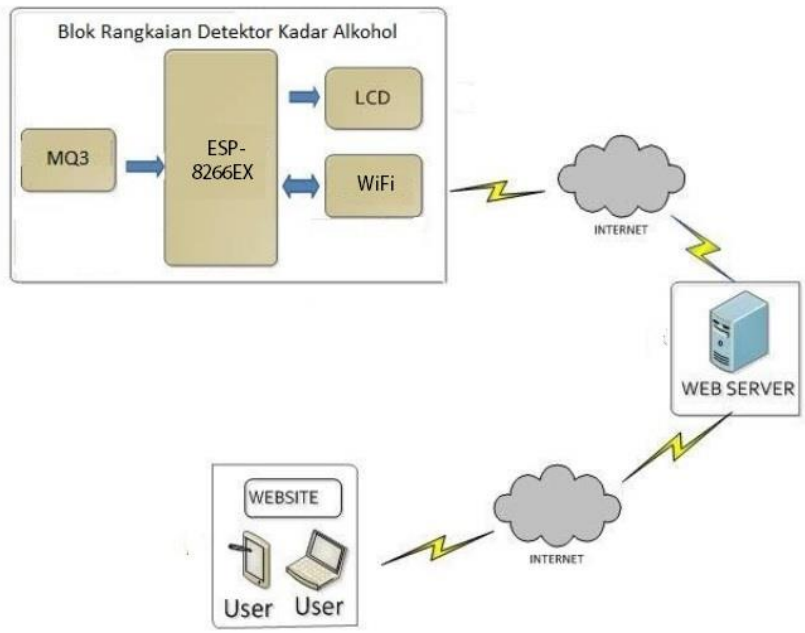

Gambar 1. Blok Diagram Deteksi Kadar Alkohol Berbasis Web

Berikut adalah bagian-bagian blok diagram deteksi kadar alkohol berbasis Web:

- Sensor MQ-3 yang berfungsi sebagai deteksi kadar alkohol. 
- Mikrokontroler ESP-8266EX yang berfungsi sebagai pusat kendali system yang akan membaca sensor MQ3 dan mengolahnya selanjutnya ditampilkan ke layar LCD dan di kirimkan ke web server melalui wemos.

- LCD 16x2 display adalah tampilan layar on-site pada alat deteksi kadar alkohol yang dapat langsung dibaca informasinya secara langsung tertera pada alat ukur.

- WeMos modul adalah komponen koneksi wireless hardware untuk koneksi secara WiFi ke jaringan internet.

- Website akan menampilkan nilai kadar alkohol pengemudi secara online menggunakan koneksi internet.

- User adalah pengguna aplikasi ini yaitu stake holder dan masyarakat umum yang memanfaatkan atau membutuhkan informasi tentang sistem deteksi kadar alkohol pengemudi.

\subsection{Tools dan Alat}

Sensor MQ-3 digunakan untuk mendeteksi kadar alkohol secara langsung [7], misalnya pada saat bernafas. Pada rangkaian driver menggunakan 1 buah variabel resistor. saja. Output dari sensor MQ-3 berupa tegangan analog yang sebanding dengan alkohol yang diterima. Menggunakan fungsi ADC untuk dapat berkomunikasi dengan mikrokontroler. ADC dapat merespon teganggan 0 5 volt. Gambar dari sensor MQ3 dapat dilihat pada Gambar 2.

Modul LCD berfungsi sebagai media penampil informasi dalam bentuk huruf/angka, yang dapat menampung 16 huruf atau angka di setiap baris [8]. Untuk gambar LCD modul dapat dilihat pada Gambar 3.

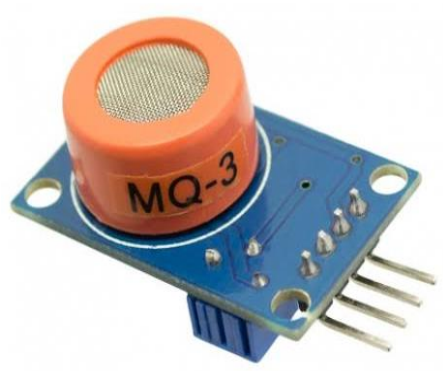

Gambar 2. Sensor Alkohol MQ-3

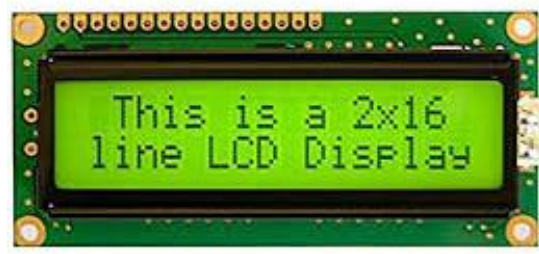

Gambar 3. LCD Display 16x2

WeMos D1 Wifi Arduino ESP8266 merupakan board mikrokontoler yang dibuat oleh Wemos dan didesain mirip dengan board arduino uno. Keunikan board Wemos D1
Wifi Arduino ESP8266 adalah kompatibilitasnya dengan Arduino IDE, jadi dapat menggunakan Arduino IDE untuk membuat / meng-compile program dan mengunduhnya ke board ini. Modul Wifi ESP8266EX memiliki prosesor 32bit / 80-160MHZ [9], [10], flash/program memori 4MB, SRAM 32KB \& DRAM 80KB tentunya dengan fitur Wifi 2,4GHZ menjadikan Wemos D1 Wifi Arduino ESP826 sebagai board yang sangat powerful dan cocok untuk internet of things. Modul Esp 8266 WiFi Wireless yang tertanam ini adalah modul wifi seri transceiver ESP8266 SoC. SOC memiliki Integrated TCP / IP stack protokol, sehingga banyak digunakan dalam jaringan, proyek kontrol ketika terhubung ke router wifi [11], [12].

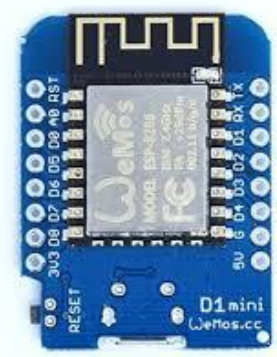

Gambar 4. WeMos D1 WiFi

Pada Gambar 4 adalah bentuk WeMos D1 mini WiFi yang mempunyai spesifikasi sebagai berikut:

a) Microkontroler ESP-8266EX.

b) Tegangan IO 3,3 Volt.

c) Digital IO: 11 dengan IO/PWM/I2C/one-wire.

d) Analog input: tegangan input maksimum 3,2 Volt.

e) Micro USB

f) Compatible dengan Arduino.

g) Compatible dengan nodeMCU.

h) Clock Speed $80 \mathrm{MHz} / 160 \mathrm{MHz}$.

i) Flash $4 \mathrm{M}$ bytes.

\subsection{Integrasi Aplikasi Web}

Aplikasi web adalah aplikasi perangkat lunak clientserver yang dapat dijalankan oleh pengguna melalui web browser [13]. Aplikasi web sangat populer dikarenakan pengguna hanya membutuhkan web browser untuk mengaksesnya tanpa harus memasang perangkat lunak tambahan dan mendukung kompatibilitas cross-platform [14]. Aplikasi web yang umum dipakai adalah webmail, jual beli online, lelang online, layanan perpesanan instan, dan lain-lainnya.

\section{Hasil dan Pembahasan}

Penelitian ini terdiri dari perangkat keras sebagai pembaca kadar alkohol dan perangkat lunak yang menampilkan hasil pembacaan kadar alkohol ke dalam Website. Alkohol yang digunakan menggunakan standart medis dan dibandingkan kadar alkohol yang telah ditentukan produsen dan hasil pengukuran menggunanakan sensor MQ-3. Pembacaan dilakukan dari tampilan LCD prototype dan tampilan pengukuran di Web. 


\subsection{Perangkat Keras}

Pada Gambar 5 adalah rangkaian detektor kadar alkohol, mikrokontroler WeMos ESP-8266EX juga sebagai koneksi jaringan $\mathrm{WiFi}$ yang akan mengirim nilai pembacaan kadar alkohol ke website.

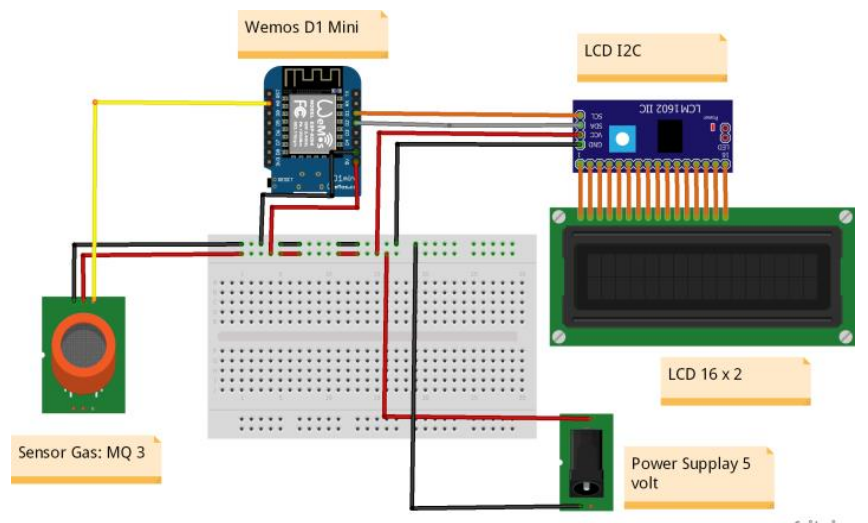

Gambar 5. Gambar Rangkaian Detektor Kadar Alkohol

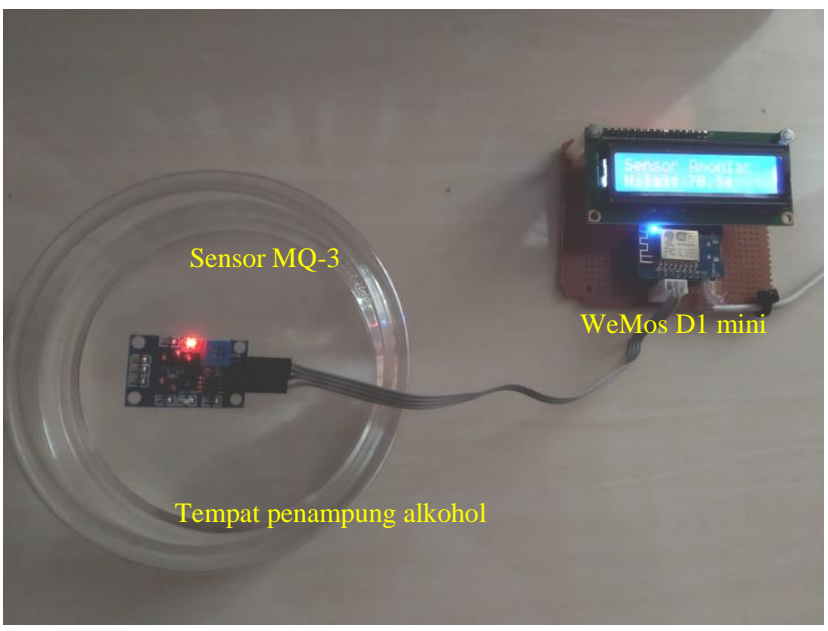

Gambar 6. Rangkaian Pengukuran Kadar Alkohol

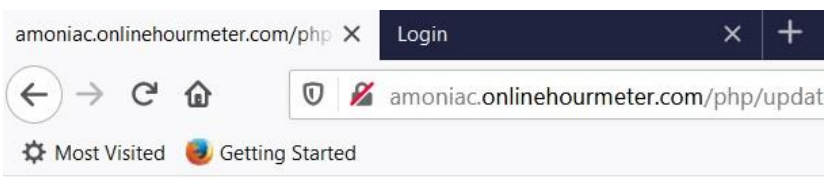

\subsection{4}

Gambar 7. Tampilan Pengujian Pengukuran Kadar Alkohol Dari Sisi Web

Perangkat keras dari penelitan ini diawali dengan blok rangkaian detector alkohol yang terdiri dari sensor MQ-3 guna mengukur kadar alkohol pada nafas pengemudi disimulasikan dengan meletakan cairan alkohol dalam ruang tertutup untuk diukur kadar alkoholnya dengan sensor MQ-3. Keluaran sensor MQ-3 adalah tegangan hasil konversi deteksi kadar alkohol. Tegangan diteruskan ke WeMos pin A0 analog input dan hasil pembacaan kadar alkohol ditampilkan ke layar LCD 16x2 melalui pin D1 dan
D2. Pengukuran dilakukan dengan menuangkan alkohol ke tempat penampungan berbentuk bulat dengan diameter 12 $\mathrm{cm}$ dan ketinggian $4 \mathrm{~cm}$ seperti terlihat pada gambar 6 . Sensor MQ-3 di buatkan lubang ke tutup penampungan alkohol untuk membaca kadar alkohol yang diuji.

\subsection{Perangkat Lunak}

Dalam pembuatan website dalam penelitian ini, dengan menggunakan bahasa pemograman PHP sebagai transaksi data atau backend dan HTML sebagai frontend atau tampilan. Dalam tampilan website akan terdapat beberapa menu seperti Login authentication dan tampilan kadar alkohol hasil pengukuran dari sensor MQ-3 yang diteruskan ke WeMos mini D1 dan dikirim melalui jaringan WiFi menuju ke jaringan internet tersambung ke Web server untuk di tampilkan.

Pengukuran kadar oksigen yang dilakukan sensor MQ-3 akan ditampilkan oleh web server seperti gambar 7. Hasil yang ditunjukkan adalah dalam nilai persentase sesuai dengan kadar alkohol yang diterima.

Tabel 1. Hasil Pengujian Kadar Alkohol Sensor MQ-3

\begin{tabular}{cccc}
\hline No & $\begin{array}{c}\text { Nama } \\
\text { Sample }\end{array}$ & $\begin{array}{c}\text { Sesuai Data } \\
\text { Produsen } \\
\text { alkohol }\end{array}$ & $\begin{array}{c}\text { Kengujian } \\
\text { Gunakan Sensor } \\
\text { MQ-3 }\end{array}$ \\
\hline 1 & $\mathrm{~A}$ & 60 & 57.25 \\
2 & $\mathrm{~B}$ & 70 & 70.34 \\
3 & $\mathrm{C}$ & 95 & 90.02 \\
\hline
\end{tabular}

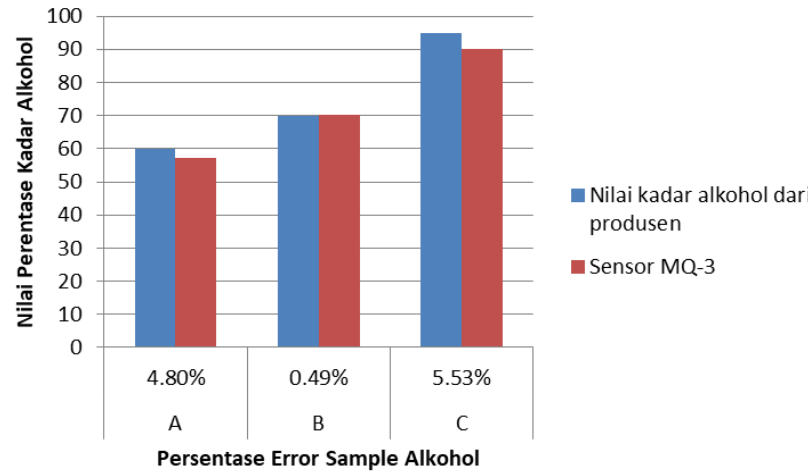

Gambar 8. Grafik Persentase Error Pengukuran Kadar Alkohol Sensor MQ-3 Berbasis Aplikasi Web

Tabel 1 menunjukkan hasil pengujian kadar alkohol perbandingan dari nilai kadar alkohol yang tertera dari produsen dibandingkan dengan pengukuran kadar alkohol dengan sensor MQ-3. Hasil pembacaan sensor MQ-3 didapat dari tampilan LCD dan tampilan di Web.

Dari tiga sample pengukuran kadar alkohol dengan alkohol yang berbeda-beda kadarnya yang ditunjukan pada Gambar 8, masing-masing pengukuran terdapat error $4,80 \%, 0.49 \%$ dan $5,53 \%$.

error $=\mid$ (referensi-nilai pengukuran)/referensi $\mid$ x $100 \%$

error $_{\text {sample } A}=|(60-57,25) / 60| \times 100 \%$

$$
=4,8 \%
$$


Ketiga persentase error pengukuran selanjutnya diambil nilai rata-rata:

Rata-rata error $=(4,8 \%+0,49 \%+5,53 \%) / 3$

$$
=3,6 \%
$$

Nilai rata-rata persentase error pengukuran didapat $3,6 \%$ nilai error ini masih termasuk baik karena dibawah $5 \%$ [15]. Pengukuran kadar alkohol yang dilaksanakan akan terbaca melalui layar LCD dan juga tampil melalui aplikasi Web. Ada selisih waktu tampilan antara di layar LCD dan tampilan di aplikasi Web yaitu rata-rata selisihnya selama 1 detik.

Penelitian ini diharapkan dapat meningkatkan kewaspadaan kita bersama dalam deteksi kadar alkohol terutama menghindari pengemudi kendaraan dalam keadaan dipengaruhi alcohol yang dapat membahayakan banyak pengguna jalan raya. Proses monitoringnya dapat di mana saja dan kapan saja karena menggunakan jaringan internet berbasis aplikasi web.

\section{Kesimpulan}

Hasil pengujian alat penelitian kita dapat mengukur dan menguji prototype penelitian sehingga kita dapat mengambil kesimpulan bahwa sistem pengukuran kadar alkohol menggunakan sensor MQ-3 telah berhasil mengukur kadar alkohol yang diuji dan pembacaannya berhasil dibaca di aplikasi web melalui perangkat WeMos dengan hasilnya sesuai dengan pembacaan di layar LCD hardware. Persentase error pengukuran dari tiga sample yang diukur didapati nilai errornya sebesar 4,80\%, 0,59\%, $5,53 \%$. Rata-rata persentase error yang didapat dari pengujian pengukuran kadar alkohol adalah sebesar 3,6\%.

\section{Daftar Pustaka :}

[1] A. Ramadhan, "Polri Sebut Jumlah Kecelakaan Lalu Lintas Meningkat pada 2019," Kompas online, Jakarta, 2019.

[2] P. Yudi Adnyana, I. Swamardika, and P. Rahardjo, "RANCANG BANGUN ALAT PENDETEKSI KADAR ALKOHOL PADA MINUMAN BERALKOHOL MENGGUNAKAN SENSOR MQ-3 BERBASIS ATmega328," J. Ilm. SPEKTRUM, vol. 2, no. 3, pp. 111116, 2015.

[3] G. Gasparesc, "Driver Alcohol Detection System Based on Virtual Instrumentation," IFAC-PapersOnLine, vol. 51, no.
6, pp. 502-507, 2018.

[4] R. Somya, "Sistem Monitoring Kendaraan Secara Real Time Berbasis Android menggunakan Teknologi CouchDB di PT. Pura Barutama," J. Nas. Teknol. dan Sist. Inf., vol. 4, no. 2, pp. 53-60, 2018.

[5] E. M. Perdana, M. Abdul, and B. Yulrio, "Rancang Bangun Pengukur Kadar Alkohol Berbasis Arduino," Coding, vol. 04, no. 2, pp. 107-118, 2016.

[6] J. Fisika, U. Andalas, K. Limau, and M. Padang, "Menggunakan Sensor MQ-137 dan Transceiver nRF24L01 +," vol. 6, no. 3, pp. 247-254, 2017.

[7] E. Antika, Y. Susmiati, and F. U. Nuha, "Perbandingan Alat Baca Kadar Bioetanol," Konf. Nas. Sist. Inf. 2018, pp. 8-9, 2018.

[8] F. P. Juniawan, D. Y. Sylfania, and R. S. Adiputra, "Prototipe Mikrokontroler Multisensor Menggunakan Arduino Uno Berbasis Web Sebagai Sistem Keamanan Rumah Prototype of Multisensor Microcontroler Using Web- Based Arduino Uno As a Home Security System," CogITo Smart J., vol. 5, no. 1, pp. 1-11, 2019.

[9] V. A. Fragastia and I. F. Rahmad, "Penerapan Internet Of Thing s ( IoT ) Untuk Mendeteksi Kadar Alkohol Pada Pengendara Mobil," no. 1, pp. 11-19, 2019.

[10] Y. Wisnuputra, E. Ihsanto, and M. H. Ibnu Hajar, "Robot Pemadam Kebakaran Berbasis Wemos," J. Teknol. Elektro, vol. 10, no. 2, p. 129, 2019.

[11] N. A. A. Kusuma, E. Yuniarti, and A. Aziz, "Rancang Bangun Smarthome Menggunakan Wemos D1 R2 Arduino Compatible Berbasis ESP8266 ESP-12F," Al-Fiziya J. Mater. Sci. Geophys. Instrum. Theor. Phys., vol. 1, no. 1, 2018.

[12] R. Rais and Y. F. Sabanise, "Sistem Monitoring Pintu Air Bendungan Menggunakan Mikrokontroler Wemos D1 R1 Berbasis Website," J. Innov. Inf. Technol. Appl., vol. 1, no. 01, pp. 51-60, 2019.

[13] G. F. Nama, A. Munif Hanafi, M. Bagus Nurfaif, and M. Tesar Sandikapura, "Dashboard Monitoring System Berbasis Web Sebagai Pemantau Layanan liteBIG Instant Messenger," J. Nas. Teknol. dan Sist. Inf., vol. 3, no. 1, pp. 19-26, 2017.

[14] M. Ismail, M. Haddin, and A. Suprajitno, "Implementasi Logika Fuzzy Untuk Akuisi Data Berbasis Web Server," Pros. SNATIF, no. 2015: Prosiding Seminar Nasional Teknologi dan Informatika, pp. 221-228, 2015.

[15] M. Ismail, J. P. Hapsari, and S. A. D. Prasetyowati, "Aplikasi Mobile Untuk Pencegahan Pencurian Kendaraan Menggunakan Protokol IEEE 802.11," Setrum Sist. Kendali-Tenaga-Elektronika-Telekomunikasi-Komputer, vol. 7 , no. 1, p. 117, 2018. 